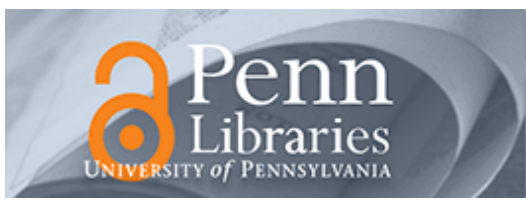

University of Pennsylvania ScholarlyCommons

Wharton Pension Research Council Working Papers

Wharton Pension Research Council

9-1-2014

\title{
Optimal Portfolio Choice in Retirement with Participating Life Annuities
}

Ralph Rogalla

Goethe University, rogalla@finance.uni-frankfurt.de

Follow this and additional works at: https://repository.upenn.edu/prc_papers

Part of the Economics Commons

Rogalla, Ralph, "Optimal Portfolio Choice in Retirement with Participating Life Annuities" (2014). Wharton Pension Research Council Working Papers. 103.

https://repository.upenn.edu/prc_papers/103

This paper is posted at ScholarlyCommons. https://repository.upenn.edu/prc_papers/103

For more information, please contact repository@pobox.upenn.edu. 


\title{
Optimal Portfolio Choice in Retirement with Participating Life Annuities
}

\begin{abstract}
This paper derives optimal consumption, investment, and annuitization patterns for retired households that have access to German-style participating payout life annuities (PLAs), allowing for capital market risks as well as idiosyncratic and systematic longevity risks. PLAs provide guaranteed minimum benefits in combination with participation in insurers' surpluses. Minimum benefits are calculated based on conservative assumptions regarding capital market and mortality developments, while surpluses distributed to annuitants bridge the gap between the insurers' actual investment and mortality experiences and the projections used in pricing. Through the participation scheme, systematic longevity risk is shared between insurers and annuitants, as unanticipated longevity shocks result in benefit adjustments via the surplus mechanism. We show that the retiree draws substantial utility from access to PLAs, equivalent to $20 \%$ of initial wealth in the presence of systematic longevity risk. We also find that stochasticity in mortality rates only has minor impact on the appeal of PLAs to the retiree. Even if the interest rate guarantee is reduced to zero in adverse capital market environments, PLAs prove to provide substantial utility for retirees. Overall, the participating life annuity design produces substantial welfare gains over a no-annuity world, while being an efficient setup that helps providers to hedge long-term risks that are difficult to hedge otherwise, such as systematic longevity risks.
\end{abstract}

\section{Keywords}

Life-cycle investing, annuitization, stochastic mortality, pension, household finance

\section{Disciplines}

Economics 


\title{
Optimal Portfolio Choice in Retirement with Participating Life Annuities
}

\author{
Ralph Rogalla
}

September 2014

PRC WP 2014-20

Pension Research Council

The Wharton School, University of Pennsylvania

3620 Locust Walk, 3000 SH-DH

Philadelphia, PA 19104-6302

Email:prc@wharton.upenn.edu

http://www.pensionresearchcouncil.org 


\title{
Optimal Portfolio Choice in Retirement with Participating Life Annuities
}

\begin{abstract}
$\underline{\text { Abstract }}$
This paper derives optimal consumption, investment, and annuitization patterns for retired households that have access to German-style participating payout life annuities (PLAs), allowing for capital market risks as well as idiosyncratic and systematic longevity risks. PLAs provide guaranteed minimum benefits in combination with participation in insurers' surpluses. Minimum benefits are calculated based on conservative assumptions regarding capital market and mortality developments, while surpluses distributed to annuitants bridge the gap between the insurers' actual investment and mortality experiences and the projections used in pricing. Through the participation scheme, systematic longevity risk is shared between insurers and annuitants, as unanticipated longevity shocks result in benefit adjustments via the surplus mechanism.

We show that the retiree draws substantial utility from access to PLAs, equivalent to $20 \%$ of initial wealth in the presence of systematic longevity risk. We also find that stochasticity in mortality rates only has minor impact on the appeal of PLAs to the retiree. Even if the interest rate guarantee is reduced to zero in adverse capital market environments, PLAs prove to provide substantial utility for retirees. Overall, the participating life annuity design produces substantial welfare gains over a no-annuity world, while being an efficient setup that helps providers to hedge long-term risks that are difficult to hedge otherwise, such as systematic longevity risks.
\end{abstract}

Keywords: Life-cycle investing, annuitization, stochastic mortality, pension, household finance

JEL: D14, G11, G22

\section{Ralph Rogalla}

Finance Department, Goethe University

Grueneburgplatz 1 (Uni-PF. H 23)

Frankfurt am Main, Germany

Phone: +49 (0)69 79833661

Email: rogalla@finance.uni-frankfurt.de 


\section{Optimal Portfolio Choice in Retirement with Participating Life Annuities}

\section{Introduction}

Around the world, ongoing demographic change puts tremendous stress on traditional social security systems, and individuals are increasingly asked to assume responsibility for their financial wellbeing in retirement. Consequently, they face the challenge of building up and maintaining an adequate portfolio of financial assets that ensures satisfying future consumption liabilities, while controlling the risks that individuals face in retirement. Against this background, this paper derives optimal consumption and portfolio choice patterns for a retired individual that has access to stocks, bonds, and participating life annuities (PLAs), while being exposed to capital market risks on the stock and bond markets as well as to idiosyncratic and systematic longevity risks.

Participating contracts are the typical product offered in the German life and annuity market (Bohnert/Gatzert, 2012; Berdin/Gründl, 2014), and they are also among the most prevalent insurance products around the world (Grosen/Jørgensen, 2000). As described in Maurer et al. (2013a), among others, participating life annuities provide guaranteed lifelong minimum annuity benefits in combination with participation in the insurer's surpluses. Minimum benefits are calculated based on conservative assumptions regarding capital market and mortality developments, while surpluses distributed to annuitants bridge the gap between the insurer's actual investment and mortality experiences and the projections used in pricing. Through the participation scheme, systematic longevity risk is shared between the insurer and the annuitants, as unanticipated longevity shocks result in benefit adjustments via the surplus mechanism. 
The literature on participating life insurance contracts is extensive. ${ }^{1}$ Most studies concentrate on actuarial risk analysis for and financial pricing of the guarantees embedded in these products (e.g. Briys/de Varenne, 1997; Grosen/Jørgensen, 2000, 2002; Ballotta, 2005; Barbarin/Devolder, 2005; Bauer et al., 2006; Gatzert/Kling, 2007; Kling et al. 2007; Zaglauer/Bauer, 2008). Others study the value of such contracts for the consumer (e.g. Gatzert et al., 2009, 2012; Maurer et al., 2013a). Yet to the best of our knowledge, optimal demand for PLAs within a lifecycle framework has not been studied as of now. While several studies integrate insurance products into a lifecycle portfolio choice model (e.g. Huang/Milevsky, 2008; Horneff et al., 2008, 2008a; Inkmann et al., 2011; Inkmann/Michaelides, 2012; Hubener et al., 2014), those papers that analyze non-fixed annuity products typically concentrate on unitlinked, variable annuities that do not include guarantees (e.g. Milevsky/Young, 2007; Horneff et al. 2009, 2010). An exception is the paper by Horneff et al. (2013a) that incorporates variable annuity products that provide both upside potential and downside protection. These guarantees, however, only cover the capital market development, as that paper does not account for variation in mortality rates. Hence, there is neither participation in the mortality performance nor a need for protection against adverse mortality developments. Maurer et al. (2013) studies annuities that provide participation in both capital market as well as mortality developments, but those products do not provide any guarantees.

The present paper contributes to the existing literature by analyzing optimal demand patterns for participating annuity contracts providing minimum income guarantees within a lifecycle consumption and portfolio choice framework that incorporates idiosyncratic and systematic mortality risk as well as investment risks in the stock and bond markets. We show that the retiree draws substantial utility from access to PLAs, equivalent to $20 \%$ of initial wealth in the presence of systematic longevity risk. We also find that stochasticity in mortality rates

\footnotetext{
${ }^{1}$ For a comprehensive overview of the literature on participating contracts see, for example, Jørgensen (2004), Bohnert/Gatzert (2012), Eling/Holder (2013).
} 
only has a minor impact on the appeal of PLAs to the retiree. Even if the interest rate guarantee is reduced to zero in adverse capital market environments, PLAs prove to provide substantial utility for retirees.

The remainder of this paper is organized as follows: Section 2 describes our lifecycle and mortality model as well as the mechanics of our PLA product. In Section 3 we derive optimal portfolio choice and annuitization patterns with and without systematic mortality risk. Moreover, we study the impact of adverse capital market development and conduct a welfare analysis. A final section concludes.

\section{Model}

\subsection{Lifecycle Framework}

We model the lifecycle of a retired male from age 65 to 100, building on and extending the setup described in Horneff et al. (2013). At the beginning of each year, the retiree receives an exogenous pension income $Y_{t}$, e.g. from Social Security or an occupational pension plan. The sum of this pension income and any pre-existing liquid wealth $W_{t}$ represents the retiree's cash on hand $X_{t}$, which is allocated to (nominal) consumption $C_{t}$, stock investments $S_{t}$, bond investments $B_{t}$, and the purchase of PLAs $P R_{t}$ :

$$
X_{t}=W_{t}+Y_{t}=C_{t}+S_{t}+B_{t}+P R_{t}
$$

At the end of each year, the retiree receives the returns on his stock and bond investments and, subject to having purchased any PLAs, an additional (nominal) annuity income $L_{t}$. Consequently, liquid wealth at the beginning of the next period is given by

$$
W_{t+1}=S_{t} \cdot R_{t}^{S}+B_{t} \cdot R_{t}^{B}+L_{t}
$$

where $R_{t}^{S}$ represents the log-normally distributed, risky nominal return on stocks and $\left(R_{t}^{B}-1\right)$ 
is the normally distributed, risky nominal yield on bonds. ${ }^{2}$ Consumption and investment decisions are made such that the retiree maximizes his expected utility, described by a recursive, additively time-separable CRRA utility function:

$$
V_{t}=\frac{\left(C_{t}\right)^{1-\rho}}{1-\rho}+\tilde{p}_{t}^{s} \cdot \beta \cdot \pi^{\rho-1} \cdot E_{t}\left[V_{t+1}\right]
$$

with terminal utility

$$
V_{T}=\frac{\left(C_{T}\right)^{1-\rho}}{1-\rho}
$$

and subject to the constraints

$$
C_{t}>0 ; \quad S_{t}, B_{t}, P R_{t} \geq 0
$$

Here, $\rho$ is the retiree's coefficient of relative risk aversion, $\beta$ his time preference, and $T$ is the maximum age 100. $\pi$ represents the annual increase in consumer prices, through which the individual accounts for inflation in his optimization exercise. Finally, $\tilde{p}_{t}^{s}$ is the retiree's subjective survival probability from $t$ to $t+1$, which is known at time $t$ but -over time- evolves according to the stochastic dynamics described in Section 2.2 below.

\subsection{Mortality Dynamics}

For modeling the stochastic dynamics of the retiree's subjective survival probabilities, we rely on the parsimonious model of Cairns, Blake, and Dowd (Cairns et al., 2006). They assume that the logits of the conditional one-year mortality rates $\tilde{q}_{x}^{t}$ at time $t$ for an individual age $x$ can be described as:

\footnotetext{
${ }^{2}$ With respect to fixed-income investments, a typical approach in the literature on portfolio choice with annuities is to assume that bonds earn a constant real rate of return. Here, we allow for stochastic variation in fixed-income returns as these fluctuations play a major role in the surplus mechanism of the PLA. We focus on the long-term government bond yield and not on the return of a diversified bond portfolio, as the guaranteed interest rate, a central parameter in the PLA mechanics, is directly tied to the long-term yield. Moreover, we work under the simplifying assumption of normally distributed yields, as the standard approach of incorporating autoregressive yields or even a fully-fledged term structure model is computationally infeasible due to the curse of dimensionality.
} 


$$
\operatorname{logit}\left(\tilde{q}_{x}^{t}\right)=\log \left(\frac{\tilde{q}_{x}^{t}}{1-\tilde{q}_{x}^{t}}\right)=A_{1, t}+A_{2, t} \cdot x
$$

The stochastic dynamics of $A_{t}=\left(A_{1, t}, A_{2, t}\right)^{T}$ are described by a two-dimensional random walk with drift:

$$
A_{t+1}=A_{t}+\mu_{A}+V_{A} Z_{t+1}
$$

with $\mu_{A}$ representing the drift of $A_{t}$ and $V_{A}$ the lower triangular matrix resulting from a Cholesky decomposition of the covariance $\Sigma_{A}$ of $A_{t} . Z_{t+1}$ is a bi-variate standard normal shock.

\subsection{PLA Mechanics}

The individual has access to participating life annuities over his retirement period and can annuitize gradually as he sees fit. When adding to his stock of PLAs, the retiree trades a nonrefundable premium $P R_{t}$ for guaranteed lifelong annuity income $\bar{L}_{t}^{a d d}$ plus non-guaranteed, stochastic surplus payments $S P_{t}$ (see e.g. Maurer et al., 2013a). The additional guaranteed income is given by:

$$
\bar{L}_{t}^{a d d}=\frac{P R_{t}}{(1+\delta) \cdot a_{x}}
$$

with the resulting total guaranteed lifelong annuity income $\bar{L}_{t+1}=\bar{L}_{t}+\bar{L}_{t}^{a d d}\left(\bar{L}_{0}=0\right) . \delta$ is an expense loading factor charged to cover the insurer's costs of operation. $a_{x}$ is the price at age $x$ of a fixed annuity paying 1 currency unit for life at the end of each year. Following the actuarial principle of equivalence, this price is calculated as:

$$
a_{x}=\sum_{t=1}^{T} \frac{{ }_{t} p_{x}^{I}}{(1+G I R)^{t}} .
$$

Here, GIR is the guaranteed interest rate promised by the insurer. ${ }_{t} p_{x}^{I}=$ $\prod_{i=0}^{t-1}\left(1-q_{x+i}^{I}\right)$ is the $t$-period survival probability for an individual aged $x$, where $q_{x+i}^{I}$ 
represents the insurer's first-order actuarial assumptions regarding the conditional 1-period mortality rates in the insured collective.

The non-guaranteed surplus payments depend on the insurer's actual experience regarding mortality and capital market returns vis-à-vis the first-order assumptions used in pricing the PLA. Following Wolfsdorf (1997) and Maurer et al. (2013a), the insurer's total surplus from mortality experience can be calculated as:

$$
g_{x, t+1}^{q}=\left(V_{t+1}+\bar{L}_{t+1}\right) \cdot\left(\tilde{q}_{x+t}-q_{x+t}^{I}\right),
$$

with actuarial reserve at time $t+1$ (after PLA payments) $V_{t+1}$ and observed mortality $\tilde{q}_{x+t}$. These mortality rates evolve stochastically as described in Section 2.2. The insurer's total surplus from capital market experience can be calculated as:

$$
g_{x, t+1}^{r}=\left(V_{t}+\frac{P R_{t}}{1+\delta}\right) \cdot\left(\tilde{r}_{t+1}-G I R\right),
$$

with $V_{t}$ the actuarial reserve at time $t$ (prior to additional PLA purchases), and $\tilde{r}_{t+1}$ the stochastic investment return on the assets backing the insurer's reserves. ${ }^{3}$ The development of the actuarial reserve over time is governed by:

$$
V_{t+1}=\frac{1}{p_{x+t}} \cdot\left(V_{t}+\frac{P R_{t}}{1+\delta}\right) \cdot(1+G I R)-\bar{L}_{t+1}
$$

with $V_{0}=0$.

Total surpluses generated from mortality experience $\left(g_{x, t+1}^{q}\right)$ and investment performance $\left(g_{x, t+1}^{r}\right)$ are shared between the insurer and the annuitants. In this regard, German regulation requires that negative surpluses are solely borne by the insurer and that surpluses from the two

\footnotetext{
${ }^{3}$ Insurers' assets can be invested into a mixed portfolio, primarily consisting of bonds with a limited exposure to equities. German insurance regulation allows for a maximum of 35\% of equity in insurer portfolios (see, among others, Maurer et al., 2013).
} 
sources must not be netted, should one be negative and one positive. Consequently, the amount of surplus attributed to the annuitant is given by:

$$
S P_{t+1}=\omega_{q} \cdot \max \left(g_{x, t+1}^{q}, 0\right)+\omega_{r} \cdot \max \left(g_{x, t+1}^{r}, 0\right),
$$

with $\omega_{q}\left(\omega_{r}\right)$ representing the annuitant’s share of mortality (investment) surplus.

\subsection{Calibration and Solution}

Drawing on standard parameterizations in the lifecycle literature, we assume a risk aversion coefficient of $\rho=5$, and a time preference parameter of $\beta=0.96$ (see, e.g, Horneff et al., 2013). In our baseline scenario, we calibrate the capital market model to historical German data for the period 1980 through 2012. For stocks, we rely on the MSCI Germany total return index. Bond returns are based on the average annual yields on German government bonds with maturities between 9 and 10 years, as provided by the Bundesbank. Inflation rates are calculated using the German CPI provided by Datastream. Based on those time series, the logreturns of stocks have a mean of $8.89 \%$ and a volatility of $25.3 \%$, while the bond yield has a mean of $5.91 \%$ and a volatility of $2.10 \% .{ }^{4}$ The correlation between the log-returns of stocks and the bond yields is 0.0004 . To reduce computational burden, we assume that annual inflation is constant at $2.2 \%$, which is equal to the average inflation rate over the calibration period and slightly above the long-term inflation target of the European Central Bank (2\%).

Subsequently, we will analyze a more unfavorable capital market scenario, which is in line with more recent developments. To this end, we calibrate our model using the same data, but we restrict the sample to the period 2000 through 2012. Hence, we include both the dotcom crisis of the early 2000s as well as the financial crisis of 2008. Here, the log-returns of stocks have a mean of $0.7 \%$ and a volatility of $30.0 \%$, while the bond yield has a mean of $3.86 \%$

\footnotetext{
${ }^{4}$ This calibration results in a small but non-zero probability for negative bond yields. In our simulation analyses we account for this by setting negative yield draws to zero.
} 
and a volatility of $1.04 \%$. The correlation between the log-returns of stocks and the bond yields is -0.47 . Annual inflation is set to $1.6 \% .^{5}$

For calibrating the CBD mortality model, we rely on data provided by the Human Mortality Database (www.mortality.org). Specifically, we use mortality data for German males age 65 - 109 over the period 1956 through 2011, the last date currently available. Based on OLS estimation, we set the drift of $A_{1}\left(A_{2}\right)$ to $-0.0374(0.0003)$, the volatility of $A_{1}\left(A_{2}\right)$ to $0.0878(0.0012)$, and the correlation between $A_{1}$ and $A_{2}$ to -0.9443 . We set the initial values for $A_{1}\left(A_{2}\right)$ at $t=0$ to $-11.2006(0.1060)$, projecting the values from the 2011 HMD dataset 2 years into the future. Furthermore, we assume that mortality and capital market shocks are uncorrelated.

First-order mortality assumptions for pricing the PLAs draw on annuitant mortality data provided by the German Association of Actuaries (DAV). Specifically, we use the "DAV 2004 R” table for males, incorporating their first-order trend to generate the cohort table for those age 65 in 2013. The guaranteed interest rate used in PLA pricing is set to $60 \%$ of the average yield on 10-year government bonds, which is the maximum return guarantee allowed under German insurance regulation (see, among others, Berdin/Gründl, 2014). Consequently, given our capital market parameterization, the GIR is set to 3.5\% for the baseline calibration, and to 2.3\% in the adverse capital market environment scenario. Due to the ongoing low-interest environment, actual GIRs for German PLAs currently stand at $1.75 \%$ and are scheduled to decrease to $1.25 \%$ starting January 2015. To account for this continuing reduction in guarantee levels, we will also study a scenario with zero GIR. In line with industry averages, the shares

\footnotetext{
${ }^{5}$ More recently, yields on German government bonds have declined even further, resulting in substantial difficulties for insurers that previously sold policies with generous, irrevocable, lifelong return guarantees. These insurers currently struggle to find adequate new investment opportunities that generate returns sufficient to cover those guarantees with limited exposure to capital market risks. Despite these developments, we refrain from narrowing down our calibration period to the most recent years, as the unprecedented decline in yields was accompanied by substantial stock price increases. It is most likely that these capital market developments cannot be sustained over a time period that corresponds with our long-term projection horizon.
} 
of mortality and investment surplus attributed to the annuitant are set to $\omega_{q}=\omega_{r}=92 \%$, the fraction of insurer reserves invested in equities is set to $10 \%$, and the expense loading factor is set to $\delta=6.6 \%$ (see Maurer et al., 2013a).

To derive the optimal policies for consumption, investment, and annuitization, we follow the standard approach and first normalize our optimization problem by the (exogenous) retirement income, in order to reduce the computational burden. Then, we employ backward induction through the five-dimensional state space $\left\{\mathrm{W}, \mathrm{L}, \mathrm{A}_{1}, \mathrm{~A}_{2}, \mathrm{t}\right\}$, relying on Gaussian quadrature integration when calculating the expected future indirect utility. Subsequently, we evaluate the resulting optimal controls by simulating 100,000 independent lifecycles for a male age 65 in 2013, whose accumulated retirement nest-egg in the form of liquid wealth amounts to four times his retirement income, the average wealth to income ratio for individuals age 60 to 70 in the 2010 wave of the German SAVE panel survey.

\section{Results}

\subsection{Base Case}

We begin our study with an analysis of the retiree's optimal consumption, investment, and annuitization patterns under systematic longevity risk and our baseline capital market calibration. Figure 1 presents the expected development of total income (i.e. Social Security and guaranteed PLA income), periodic annuity purchases, annuitized wealth, liquid wealth, and inflation-adjusted consumption as well as the development of the allocation of total wealth to our three asset classes stocks, bonds, and (participating life) annuities over time. We illustrate these parameters for two different surplus distribution schemes. On the left, Panel A shows the results under the assumption that PLA surpluses are paid as life annuities, i.e. surpluses increase the amount of guaranteed lifelong income. On the right, Panel B shows the results under the alternative assumption that PLA surpluses are paid out immediately as lump sums. 
We first turn to Panel A of Figure 1. At age 65, the beginning of the retirement phase, the individual shifts a substantial fraction of his financial means into the annuity product. PLA purchases amount to 1.94 times the pension income, roughly 39\% of initial cash on hand. The retiree decides to consume about 1.07 times the pension income and the remaining funds of 1.99 times the pension income are held in liquid asset, primarily stocks. The resulting asset allocation is $50 \%$ stocks, $2 \%$ bonds, and $48 \%$ PLAs, where the value of PLA holdings is calculated as the amount of guaranteed lifelong annuity income times the age-specific annuity factor.

In subsequent periods, the retiree continues to steadily annuitize. Yet the level of additional PLA purchases drops measurably, ranging between 0.3 and 0.4 times the pension income until the mid 90s and then gradually decreasing toward the end of the lifecycle. Small purchases of additional PLAs suffice, because all surpluses earned on PLA holdings are also annuitized, resulting in both increasing annuity wealth as well as annuity income. Annuity wealth peaks in the early 90s at around 8.3 times the pension income and then drops to zero as the individual reaches the end of the lifecycle.

With total income increasing measurably due to continued annuitization, the retiree is not only able to maintain his consumption level but can even increase it in real terms. Over the whole retirement period, inflation-adjusted consumption almost triples from the initial 1.07 to 3.13 at age 100.

Despite the increase in consumption, liquid wealth holdings remain almost constant during the first decade in retirement, and only from age 75 we see a measurable drawdown that continues until the end of the lifecycle. While the overall share of liquid wealth decreases with increasing annuity wealth, the bond share remains fairly constant at around $2 \%$ until age 75 , which leads to marginal de-risking of liquid wealth. Subsequently, however, bonds are gradually crowded out of the portfolio until the late 80s. 
Next, we turn to Panel B of Figure 1 that presents optimal household behavior when PLA surpluses are paid out as lump sums. As in the previous setup, the retiree spends a substantial amount of his financial means on PLA purchases at age 65. With 1.87 times his pension income, this number initially falls slightly short of that in the case of surplus annuitization. Subsequently, however, annual PLA purchases constantly amount to around 0.5 times the pension income, $60 \%$ above those in the previous case. Higher PLA purchases come as no surprise, as annuity income no-longer increases automatically when PLAs generate surpluses. Moreover, while surplus annuitization is free of administrative charges, the retiree here has to pay expense loadings for every increase in annuity income. Nonetheless, the allocation of funds to PLA purchases is high enough to overcompensate both the lack of surplus annuitization and the higher administrative charges. Consequently, annuitized wealth as well as total income are higher than in the case of surplus annuitization until the early 80s. Subsequently, however, neither annuitized wealth nor income can keep up with their counterparts in the first setup. Annuity wealth peaks at 7.13 times the pension income around age 90 . The same holds for income, which is down by about $25 \%$ at the end of the lifecycle.

The higher PLA purchases early in retirement are in no small part financed by withdrawals from liquid wealth. By age 75 , already around $50 \%$ of initial liquid wealth has been spent, and around age 90, liquid wealth has been depleted. This also has implications for the asset allocation. While initially $48 \%$ of the retiree's wealth is invested in stocks, $6 \%$ in bonds, and $46 \%$ in PLAs, bonds are quickly crowded out by PLAs. At age 70, the individual already holds $76 \%$ of his wealth in PLAs and $24 \%$ in stocks. PLAs exhibit bond-like characteristics, and since -in this case- some of their returns are distributed in the form of liquid lump sums, there is no need for holding liquid bonds.

Over the first couple of periods, average consumption exceeds that in the surplus annuitization scenario by about $2 \%$. Subsequently, higher PLA prices take their toll on 
consumption opportunities, which increasingly fall short of those in the previous case. By age 90, the gap in average annual inflation-adjusted consumption has risen to $3.5 \%$ and continues to increase to about $22 \%$ until the end of the lifecycle.

\subsection{Impact of Systematic Mortality Risk}

In the context of our model, mortality rates and their potential uncertainty influence the retiree's optimal portfolio choice and annuitization decisions via two competing channels. First, they have an immediate impact on the subjective discount rates in the individual's intertemporal utility function, as described in Equation 3. The higher (lower) the retiree's mortality rates, the lower (higher) the appeal of prospective future consumption and, hence, the lower (higher) the appetite for the lifelong income stream from PLAs. On the other hand, higher (lower) mortality rates have a positive (negative) impact on the level of cash flows provided by the PLAs through the mortality surplus mechanism discussed in Section 2.3. These cash flows, however, are conditional on being alive at the time of payment. The impact of mortality rate stochasticity on the trade-off between these two opposing effects and the resulting implications for PLA demand are not obvious. This section aims at shedding more light on this issue.

Figure 2 first provides a deeper insight into the implications of systematic mortality risk on the surplus mechanism within our PLA setup and given the German mortality data we calibrated the model to. The figure depicts the differences between actual mortality rates $\left(\tilde{q}_{t}\right)$ and the first-order mortality assumptions $\left(q_{t}^{I}\right)$ over time. As described in Equation 10, these differences are the central determining factor for the mortality surpluses generated within the PLA. Figure 2 presents these quantities for two alternative mortality dynamics. First, the solid black line shows the values under a trend-only mortality regime, which assumes that the evolution of mortality rates is deterministic. Specifically, we assume that mortality rates follow the process described in Section 2.2, but with the shocks $Z_{t}$ in Equation 7 equal to zero. Second, the blue fan chart depicts the distribution of the differences in mortality rates from our baseline 
model with stochastic mortality (5\% to $95 \%$ quantile based on 100,000 simulation runs, with darker areas having higher probability mass). In case the difference is positive, actual mortality rates $\left(\tilde{q}_{t}\right)$ exceed the rates assumed when pricing the PLA $\left(q_{t}^{I}\right)$.

Figure 2 here

With trending mortality, actual mortality $\left(\tilde{q}_{t}\right)$ always exceed assumed mortality $\left(q_{t}^{I}\right)$, and the PLA continuously generates mortality surpluses. Small early in retirement (about $0.5 \%$ at age 65), the difference in mortality rates gradually increases to around $1.2 \%$ at age 80 . Under the surplus annuitization scheme and given our mortality surplus participation rate $\left(\omega_{q}\right)$ of $92 \%$, this difference translates into an increase in lifelong annuity income of about $1.1 \%$ in that particular year. Subsequently, the gap in mortality rates decreases until they are almost equal at age 90 , before it steeply increases to about $5 \%$ at the end of the lifecycle.

Under stochastic mortality, the general pattern of the differences in mortalities is of course preserved, as mortality rates randomly fluctuate around said trend with volatilities increasing with time horizon. Throughout the first decade and a half in retirement, dispersion of mortality rate differences is moderate. Hence, by age 80 , surplus-generating mortality rate differences still exceed $0.5 \%$ for $95 \%$ of all mortality developments. Subsequently, however, the range of possible outcomes widens sharply. Around age 84, the fan chart intersects with the zero line, indicating that $5 \%$ of simulated mortality developments result in negative mortality rate differences and in PLAs producing mortality losses. By age 90, PLAs generate negative surpluses in almost $50 \%$ of the simulation runs, a number that drops to around $22 \%$ until the end of the lifecycle. Due to the guarantees embedded in PLAs, these mortality losses are borne by the insurer (see Equation 13 ). ${ }^{6}$ Hence, should mortality rates decrease substantially, the

\footnotetext{
${ }^{6}$ From the perspective of the insurer, the probability of negative mortality surpluses at advanced ages of the annuitant is substantial. By that age, however, the remaining actuarial reserve is already comparably small. As the absolute pecuniary loss suffered by the insurer depends on both the mortality rate difference as well as the actuarial reserve, the insurer may well be able to sustain them.
} 
retiree can enjoy the longer lifetime while still receiving at least the guaranteed minimum annuity income. On the other end of the distribution, $50 \%$ of simulation runs produce mortality rate differences exceeding $4 \%$ toward the end of the lifecycle, and in the $5 \%$ cases with highest mortality rates, differences even top $13 \%$. Hence, in case of survival, substantial mortality credits can be expected.

Next, we turn to Figure 3, which shows the impact of stochastic mortality rates on the distribution of PLA purchases over time. Again, Panel A on the left depicts the results for the surplus annuitization scheme, while Panel B on the right presents the surplus lump sum case. At the top of each panel, we present the distribution of annuity purchases under stochastic mortality, while the results under trending mortality regime are shown at the bottom. As in Figure 2, the fan charts depicted here describe the 5\%:95\% range of the purchase distribution, with darker areas representing higher probability mass.

Under the surplus annuitization scheme, early in retirement, the stochastic mortality scenario produces a PLA purchase distribution that is comparable to that in the trending mortality scenario. In both cases, the differences in PLA purchases between the $5 \%$ and the 95\% quantile amount to between 0.4 and 0.5 times the pension income over the first 15 years in retirement. The distribution under trending mortality, however, is shifted upward by an average 0.04 times the pension income, indicating that PLAs are marginally more sought after than under stochastic mortality. Yet in that phase of the lifecycle, stochasticity in mortality rates has negligible impact on demand, which corresponds to our insights from Figure 2 earlier in this section. Consequently, early in retirement, differences in PLA purchases across simulated lifecycles must primarily be driven by other stochastic factors, namely capital market developments.

Figure 3 here 
At advanced ages, this picture changes dramatically. Under trending mortality, from age 90, the purchase distribution collapses to an almost deterministic pattern, with differences in PLA purchases between the $5 \%$ and the $95 \%$ quantile amounting to a mere 0.07 times the pension income, on average. By contrast, stochastic mortality rates trigger differentiated annuitization patterns. While the range of PLA purchases is smaller than early in retirement, the difference between the $5 \%$ and the $95 \%$ quantile still averages 0.36 times the pension income.

The surplus lump sum scenario in Panel B of Figure 3 exhibits a comparable pattern. Yet, the range of PLA purchases is wider than under surplus annuitization, both earlier as well as later in the lifecycle. Without automatic annuitization of surpluses, deliberate PLA purchases more strongly depend on the development of PLA surpluses and, hence, on the stochastic development of the mortality rates.

\subsection{Impact of Adverse Capital Market Environments}

Having discussed how mortality developments influence the performance of PLAs and their attractiveness to retirees in the previous section, we now turn to the second driver of PLA benefits: the capital market. In particular, we will discuss how the retiree adjusts annuitization and asset allocation patterns over the lifecycle if capital markets generate less generous returns than in our baseline calibration. Against this background, we will study the appeal of PLAs under two alternative product specifications. In the first setup, the GIR will again be set to $60 \%$ of the average bond yield, and the share of surplus attributed to the annuitant will again be set to the market average of $92 \%$. In the second setup, we assume that the insurer reacts to the adverse developments in the capital markets by reducing the generosity of the PLA. Specifically, we assume that guarantees are cut by setting the GIR equal to zero. In addition to that, we assume that the insurer reduces surplus attributions to the annuitant to the minimum currently stipulated by the German regulator. The minimum share for asset surpluses $\left(\omega_{r}\right)$ is 
$90 \%$, while that for mortality surpluses $\left(\omega_{q}\right)$ is $50 \%$. Table 1 presents the resulting expected developments of total income, PLA purchases, annuity wealth, liquid wealth, and inflationadjusted consumption at selected ages for both the surplus annuitization scheme as well as the surplus lump sum scheme. Panel A summarizes our findings for the baseline capital market calibration, as discussed in Section 3.1. Panels B and C present the results under the alternative calibration for the two PLA specifications. The corresponding Table 2 presents the expected developments of the asset allocation.

Table 1 here

As one would expect, the adverse capital market environment leaves the retiree worse off than under the baseline regime. Comparing Panels A and B in Table 1, both income and total wealth (annuitized plus liquid) in the crisis setup fall short of their counterparts under the more favorable calibration. This also holds for inflation-adjusted consumption, despite the fact that annual inflation is $0.6 \%$ below baseline inflation, i.e. more than one quarter. The reduced prospects of earning excess returns in the stock market reduce the opportunity costs of annuitization, and the retiree draws down liquid assets more quickly. By contrast, PLA purchases under the surplus annuitization scheme initially increase by $26 \%$ and subsequently remain at the baseline level, despite the reduced means available. Still, PLA income and wealth cannot keep up with the baseline values as lower capital market returns imply less asset surpluses. Results are comparable under the surplus lump sum setup, where initial PLA purchases increase by even $60 \%$. Subsequently, however, investments in additional annuities fall short of those in the base case by about $15 \%$, on average.

The change in return prospects and annuitization patterns has substantial impact on the retiree's asset allocation, particularly early in retirement. As shown in Table 2, initial equity allocations drop from around 50\% to less than 5\% under both the surplus annuitization as well as the surplus lump sum regime, and a few years into retirement, stock holdings are negligible. 
By contrast, the initial allocation to PLAs increases from $48 \%$ to $61 \%$ under surplus annuitization, and from $46 \%$ to over $75 \%$ under the surplus lump sum scheme. Subsequently, PLA allocations remain high and in excess of the baseline levels. As stocks become less desirable, the appeal of bonds increases. This particularly holds under surplus annuitization, as in this case bonds are the only alternative to stocks that also provides some liquidity and flexibility. While marginal in the base case, bond allocations now average about 36\%, initially, and remain at a measurable level well into retirement. Results under surplus distribution via lump sums are comparable, yet less pronounced, as the annual lump sums reduce the need for flexibility from liquid assets.

Table 2 here

Now, we turn to the case where the insurer reduces both the GIR as well as the surplus attribution in reaction to the adverse capital market environment (Panel $\mathrm{C}$ in Tables 1 and 2). Cutting GIR to zero drives up PLA prices due to the lack of discounting (as per Equation 9). Consequently, a given premium payment buys less guaranteed income. At the same time, this cut increases the likelihood of generating positive asset surpluses as well as their level (as per Equation 11). Depending on the surplus distribution mechanism, these two effects have different impact on the retiree.

Under the surplus lump sum scheme, the increase in asset surplus potential has an immediate positive impact on the annuitant, while he is free to choose whether to purchase additional (more expensive) PLAs. Hence, PLAs are still attractive for the retiree. He increases initial PLA purchases from 2.99 times the pension income in Panel B to 3.33, here. Consequently, he receives an initial guaranteed income of about $85 \%$ of that in the non-zero GIR case, despite the increase in PLA prices. Yet subsequent expenditure on new annuities is essentially equal to that in Panel $\mathrm{B}$, which results in an increasing income gap due to the PLA price difference. In terms of overall asset allocation, the initial increase in PLA purchases drives 
up the portfolio share of annuities by almost nine percentage points to around $84 \%$ at retirement. This increase primarily comes out of bonds, due to the bond-like nature of PLAs, whereas the equity share is almost unchanged. Later in retirement, the impact of the initial purchase diminishes, and the allocation is comparable to that in Panel B.

Under the surplus annuitization scheme, the initial attractiveness of PLAs is reduced, due to higher annuity premiums and the lack of compensatory immediate access to the potentially higher asset surplus. Initial PLA purchases drop from 2.44 times the pension income in Panel B to only 0.96. Given this reduction in expenditure and the increase in PLA prices, the initial guaranteed income is only about $30 \%$ that in the non-zero GIR case. Accordingly, the asset allocation is substantially shifted away from annuities. While in Panel B the initial PLA share was more than $60 \%$, it now averages around only $23 \%$. Two-thirds of the retiree's assets are initially invested in bonds, compared to about one-third in Panel B, with the remaining 10\% being held in stocks. As in the surplus lump sum scenario, PLA purchases and allocations converge to the respective values in Panel B later in retirement when the annuity becomes more attractive due to the survival credit. However, neither the annuity income nor inflation-adjusted consumption can catch up with their counterparts in Panel B, leaving the individual worse off than before.

Some of the reduced attractiveness of PLAs in the last scenario of course has to be attributed to the reduced generosity of surplus attribution to the annuitant. Most of this reduction affected the mortality surplus, which was cut by almost 50\%, whereas the reduction in asset surplus attribution was negligible. From our analysis in Section 3.2, however, we know that for most of the lifecycle mortality surpluses are comparably small, on average. They only gain substantial impact very late in life and in the tails of the mortality distribution. Hence, reductions related to the decrease in GIR dominate the effects of the changes with respect to the mortality surplus. 


\subsection{Welfare Implications}

Finally, we seek to appraise the utility that the retiree can draw from having access to PLAs. To this end, we perform a welfare analysis, employing the approach described in Horneff et al. (2009) and Horneff et al. (2013). We equate the retiree's expected total utilities from a setup with and without access to PLAs by adjusting his initial wealth. In doing so, we can assign a monetary value to the difference in utilities. The results are shown in Table 3, which presents the fractions of initial wealth the retiree would be willing to forego in exchange for getting access to the PLA.

Table 3 here

When PLA surpluses are annuitized, the retiree in our baseline scenario with stochastic mortality values PLA access at about $20.5 \%$ of his initial endowment. In the more predictable scenario with deterministically trending mortality, this number increases by about 3\%. Hence, utility losses from exposure to systematic mortality risk and the resulting PLA benefit volatility are only moderate. Given the guarantees embedded and the lack of desirable investment alternatives, PLAs also prove to be valuable in times of capital market turmoil. Given our parameterization, the retiree would be willing to trade one-quarter of his wealth for the opportunity to annuitize. This, of course, only holds as long as the provider does not have to reduce the generosity of the product. But even if the guaranteed interest rate was cut to zero and surplus attributions were reduced to the regulatory minimum, PLAs provide ample utility gains in the amount of almost $18 \%$ of initial wealth.

In line with findings reported in Maurer et al. (2013a), PLAs provide even higher utility gains under the surplus lump sum regime: $27.4 \%$ in our base case and almost one-third in the adverse capital market environment. This result may appear surprising at first, given that periodically changing surpluses induce PLA payout volatility. Due to the lump sum payments, however, the annuitant receives benefits earlier. Not only does surplus annuitization delay 
payouts, it also results in strongly increasing benefit levels and dispersions late in life, making it difficult to smooth consumption over the lifecycle. Intriguingly, under the surplus lump sum scheme, the PLA even generates high levels of utility (27.6\%) when the interest guarantee is reduced. This is related to the increased potential for surplus generation, as already discussed in the previous section.

\section{Conclusion}

We study optimal consumption, asset allocation, and annuitization patterns for a retired individual that has access to participating payout life annuities (PLAs), while facing capital market risks as well as idiosyncratic and systematic longevity risks. PLAs provide guaranteed lifelong minimum annuity benefits and the opportunity to participate in surpluses from the insurer’s capital market and mortality experience.

We find that it is optimal to shift a substantial fraction of available financial resources, almost $50 \%$, into the PLA already right at retirement. This is driven by the possibility to participate in positive investment returns while being protected to some extent against adverse capital market developments by the minimum benefits guaranteed in the PLA. Subsequently, gradual annuitization continues until the end of the lifecycle. PLAs are highly valuable for the retiree, who is willing to give up more than $20 \%$ of initial wealth to get access to the annuity product.

We also find that stochasticity in mortality rates only has a minor impact on the appeal of PLAs to the retiree. Given the fact that period-to-period changes of mortality rate are minuscule, systematic longevity risk only has a long-term impact on PLA purchases. Consequently, in the absence of stochastic mortality, the retiree’s willingness to pay for access to PLA markets only increases by $3 \%$ of initial wealth. 
It is intuitively clear that the annuity product is more valuable in adverse capital market environments, due to the guarantees embedded in the PLA contract. This, however, relies on the premise that the insurer will continue to be able to pay the guaranteed benefits - a questionable assumption given current developments in the capital markets. A possible approach to react to the current situation is to reduce guaranteed interest rates to zero. Our results indicate that such a policy would only have a minor negative impact on the attractiveness of the product, particularly in a situation of increased capital market risks. 


\section{References}

Ballotta, L., 2005. A Lévy Process-based Framework for the Fair Valuation of Participating Life Insurance Contracts. Insurance: Mathematics and Economics 37, 173-196.

Barbarin, J., Devolder, P., 2005. Risk Measure and Fair Valuation of an Investment Guarantee in Life Insurance. Insurance: Mathematics and Economics 37, 297-323.

Bauer, D., Kiesel, R., Kling, A., Ruß, J., 2006. Risk-neutral valuation of participating life insurance contracts. Insurance: Mathematics and Economics 39, 171-183.

Berdin, E., Gründl, H., 2014. The Effects of a Low Interest Rate Environment on Life Insurers. ICIR Working Paper Series 15/2014, Available at SSRN:

http://ssrn.com/abstract=2439171.

Bohnert, A., Gatzert, N., 2012. Analyzing Surplus Appropriation Schemes in Participating Life Insurance from the Insurer's and the Policyholder's Perspective. Insurance: Mathematics and Economics 50, 64-78.

Briys, E., de Varenne, F., 1997. On the risk of life insurance liabilities: debunking some common pitfalls. Journal of Risk and Insurance 64, 673-694.

Cairns, A., Blake, D., Dowd, K., 2006. A Two-factor Model for Stochastic Mortality with Parameter Uncertainty: Theory and Calibration. Journal of Risk and Insurance 73, 687-718.

Eling, M., Holder, S., 2013. The Value of Interest Rate Guarantees in Participating Life Insurance Contracts: Status Quo and Alternative Product Design. Insurance: Mathematics and Economics 53, 491-503.

Gatzert, N., Holzmüller, I., Schmeiser, H., 2012. Creating Customer Value in Participating Life Insurance. Journal of Risk and Insurance 79, 645-670.

Gatzert, N., Huber, C., Schmeiser, H., 2009. On the Valuation of Investment Guarantees in Unit-Linked Life Insurance: A Customer Perspective. Geneva Papers on Risk and Insurance 36, 3-29.

Gatzert, N., Kling, A., 2007. Analysis of Participating Life Insurance Contracts: A Unification Approach. Journal of Risk and Insurance 74, 547-570.

Grosen, A., Jørgensen, P.L., 2000. Fair valuation of life insurance liabilities: the impact of interest rate guarantees, surrender options and bonus policies. Insurance: Mathematics and Economics 26, 37-57.

Grosen, A., Jørgensen, P.L., 2002. Life Insurance Liabilities at Market Value: An Analysis of Insolvency Risk, Bonus Policy, and Regulatory Intervention Rules in a Barrier Option Framework. Journal of Risk and Insurance 69, 63-91. 
Horneff, V., Kaschützke, B., Maurer, R., Rogalla, R., 2013. Welfare implications of product choice regulation during the payout phase of funded pensions. Journal of Pension Economics and Finance (forthcoming). DOI: 10.1017/S1474747213000346.

Horneff, V., Maurer, R., Mitchell, O.S., Rogalla, R., 2013a, Optimal Life Cycle Portfolio Choice with Variable Annuities Offering Liquidity and Investment Downside Protection. NBER Working Paper 19206, available at: http://www.nber.org/papers/w19206.

Horneff, W., Maurer, R., Mitchell, O.S., Stamos, M., 2009. Asset Allocation and Location over the Life Cycle with Survival-Contingent Payouts. Journal of Banking and Finance 33, 1688-1699.

Horneff, W., Maurer, R., Mitchell, O.S., Stamos, M., 2010. Variable Payout Annuities and Dynamic Portfolio Choice in Retirement. Journal of Pension Economics and Finance 9, 163183.

Horneff, W., Maurer, R., Stamos, M., 2008. Optimal Gradual Annuitization: Quantifying the Costs of Switching to Annuities. Journal of Risk and Insurance 75, 1019-1038.

Horneff, W., Maurer, R., Stamos, M., 2008a. Life-Cycle Asset Allocation with Annuity Markets. Journal of Economic Dynamics and Control 32, 3590-3612.

Huang, H., Milevsky, M., 2008. Portfolio Choice and Mortality-Contingent Claims: The General HARA Case. Journal of Banking and Finance 32, 2444-2452.

Hubener, A., Maurer, R., Rogalla, R., 2014. Optimal Portfolio Choice with Annuities and Life Insurance for Retired Couples. Review of Finance 18, 147-188.

Inkmann, J., Lopez, P., Michaelides, A., 2011. How Deep is the Annuity Market Participation Puzzle? Review of Financial Studies 24, 279-319.

Inkmann, J., Michaelides, A., 2012. Can the Life Insurance Market Provide Evidence for a Bequest Motive? Journal of Risk and Insurance 79, 671-695.

Jørgensen, P.L., 2004. On Accounting Standards and Fair Valuation of Life Insurance and Pension Liabilities. Scandinavian Actuarial Journal 5, 372-394.

Kling, A., Richter, A., Ruß, J., 2007. The Impact of Surplus Distribution on the Risk Exposure of With-Profit Life Insurance Policies including Interest Rate Guarantees. Journal of Risk and Insurance 74, 571-589.

Maurer, R., Mitchell, O.S., Rogalla, R., Kartashov, V., 2013. Lifecycle Portfolio Choice with Systematic Longevity Risk and Variable Investment-Linked Deferred Annuities. Journal of Risk and Insurance 80, 649-676.

Maurer, R., Rogalla, R., Siegelin, I., 2013a. Participating Payout Life Annuities: Lessons From Germany. ASTIN Bulletin 43, 159-187.

Wolfsdorf, K., 1997. Versicherungsmathematik, Teil 1 Personenversicherungsmathematik. Stuttgart: Teubner. 
Zaglauer, K., Bauer, D., 2008. Risk-neutral valuation of participating life insurance in a stochastic interest rate environment. Insurance: Mathematics and Economics 43, 29-40. 
Figure 1: Expected Lifecycle Profiles - Baseline Calibration

Panel A: Surplus Annuitization
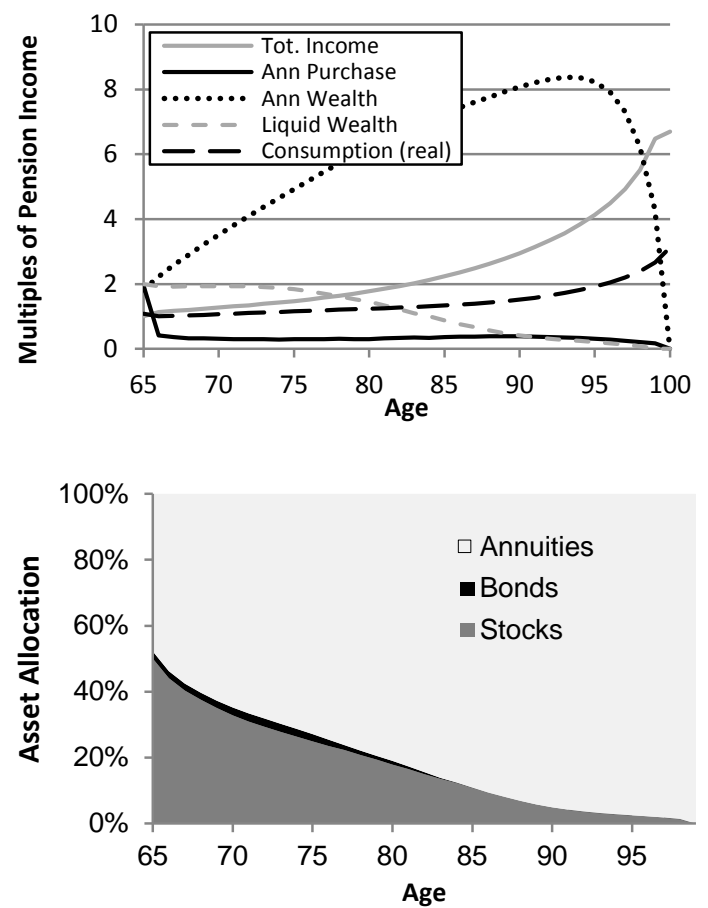

Panel B: Surplus Lump Sum
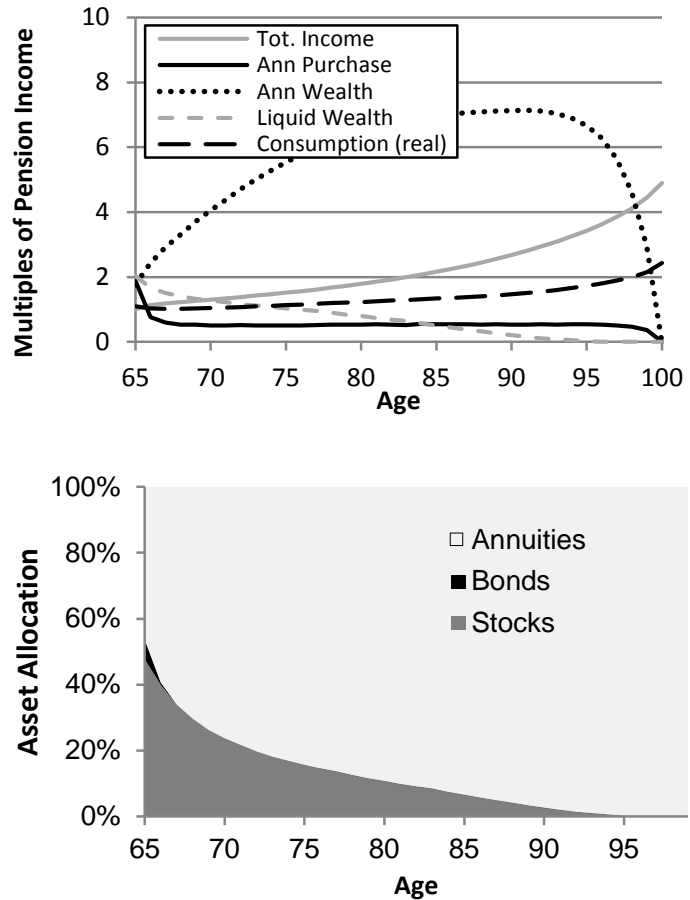

Notes: Male retiree age 65. Stochastic mortality. Log-return stocks (bond yield): mean 8.89\% (5.91\%), volatility: 25.3\% (2.1\%). Annual inflation: 2.2\%. PLA pricing assumptions: Mortality: DAV 2004 R (year 2013) plus trend, $G I R=3.5 \%, \omega_{r}=0.92 . \omega_{q}=0.92 .$. Source: Authors' calculation. 
Figure 2: Differences between First- and Second-Order Mortality Rates over Time

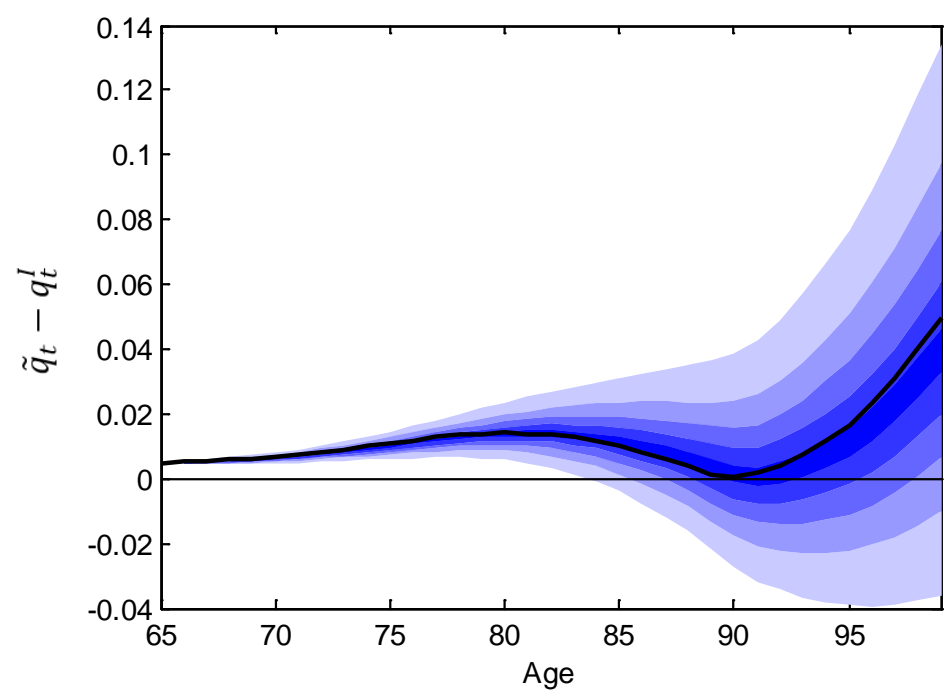

Notes: Simulated distributions of age-specific differences between actual mortality rate $\tilde{q}_{t}$ from CBD model and first-order mortality rate $q_{t}^{I}$ from DAV $2004 \mathrm{R}$ plus trend. Fan chart: 5\%-95\% quantile range of the difference distribution with darker areas representing higher probability mass. Solid black line: difference in trending mortality scenario. Source: Authors' calculation. 
Figure 3: Distributional Implications of Stochastic Mortality on PLA Purchases

Panel A: Surplus Annuitization
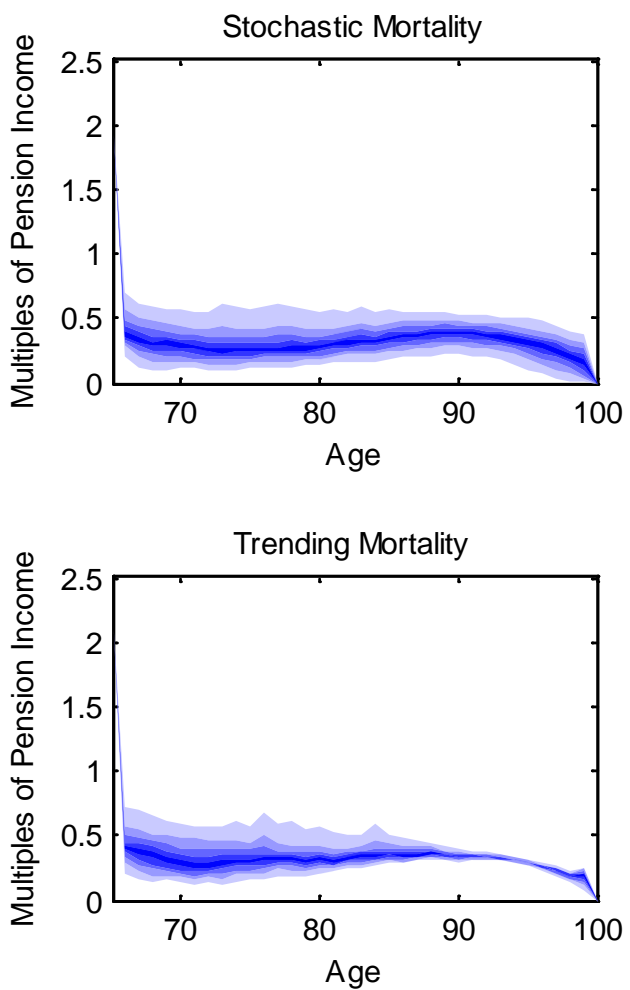

Panel B: Surplus Lump Sum
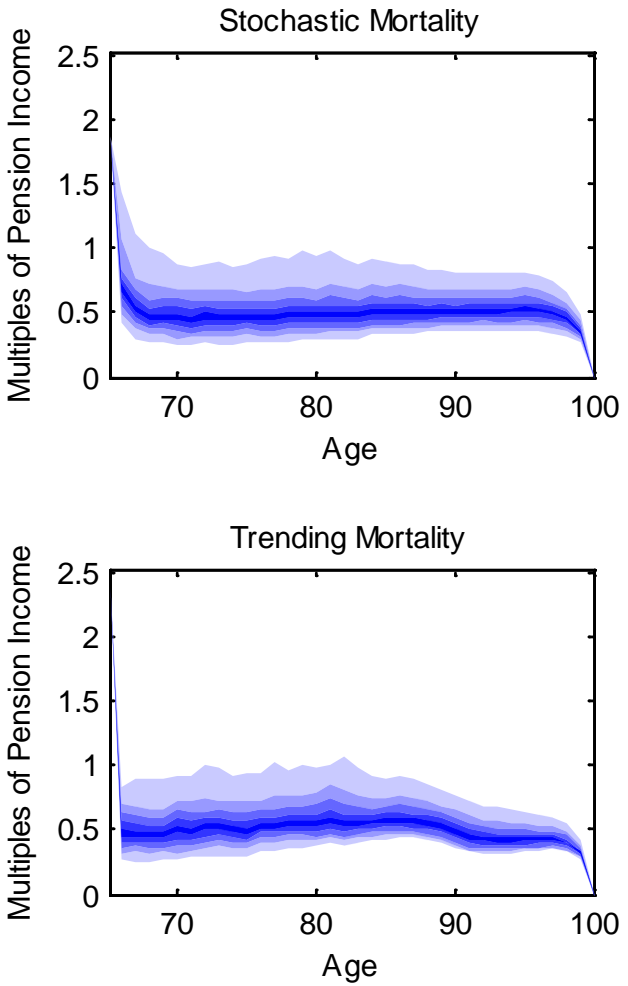

Notes: 5\%-95\% quantile range of simulated periodic PLA purchases with darker areas representing higher probability mass. Male retiree age 65. Log-return stocks (bond yield): mean: 8.89\% (5.91\%), volatility: 25.3\% (2.1\%). Annual inflation: 2.2\%. PLA pricing assumptions: Mortality: DAV $2004 \mathrm{R}$ (year 2013) plus trend, GIR = 3.5\%, $\omega_{r}=0.92, \omega_{q}=0.92$. Source: Authors' calculation. 
Table 1: Expected Lifecycle Profiles - Alternative Calibrations

\begin{tabular}{|c|c|c|c|c|c|c|c|c|}
\hline & \multicolumn{4}{|c|}{ Surplus Annuitization } & \multicolumn{4}{|c|}{ Surplus Lump Sum } \\
\hline & \multicolumn{4}{|c|}{ Age } & \multicolumn{4}{|c|}{ Age } \\
\hline & 65 & 75 & 85 & 95 & 65 & 75 & 85 & 95 \\
\hline \multicolumn{9}{|c|}{ A: Baseline Capital Market Calibration (1980 - 2012) } \\
\hline Total Income & 1.00 & 1.47 & 2.23 & 4.13 & 1.00 & 1.51 & 2.16 & 3.43 \\
\hline Annuity Purchases & 1.94 & 0.29 & 0.36 & 0.31 & 1.87 & 0.51 & 0.54 & 0.54 \\
\hline Annuity Wealth & 1.82 & 4.92 & 7.25 & 8.23 & 1.76 & 5.53 & 6.98 & 6.67 \\
\hline Liquid Wealth & 1.99 & 1.83 & 0.88 & 0.21 & 2.04 & 1.03 & 0.50 & 0.02 \\
\hline Consumption (real) & 1.08 & 1.15 & 1.34 & 1.92 & 1.09 & 1.13 & 1.33 & 1.72 \\
\hline \multicolumn{9}{|c|}{ B: Crisis Capital Market Calibration (2000 - 2012) } \\
\hline Total Income & 1.00 & 1.45 & 2.04 & 3.50 & 1.00 & 1.49 & 2.00 & 3.07 \\
\hline Annuity Purchases & 2.44 & 0.28 & 0.35 & 0.32 & 2.99 & 0.43 & 0.46 & 0.48 \\
\hline Annuity Wealth & 2.29 & 5.07 & 6.51 & 6.83 & 2.81 & 5.73 & 6.40 & 5.88 \\
\hline Liquid Wealth & 1.50 & 0.90 & 0.51 & 0.17 & 0.93 & 0.49 & 0.33 & 0.01 \\
\hline Consumption (real) & 1.07 & 1.01 & 1.26 & 1.91 & 1.08 & 1.05 & 1.31 & 1.79 \\
\hline \multicolumn{9}{|c|}{ C: Crisis Capital Market Calibration (2000 - 2012), GIR = 0, Minimum Surplus Distribution } \\
\hline Total Income & 1.00 & 1.29 & 1.79 & 3.15 & 1.00 & 1.39 & 1.85 & 2.87 \\
\hline Annuity Purchases & 0.96 & 0.24 & 0.30 & 0.28 & 3.33 & 0.48 & 0.48 & 0.50 \\
\hline Annuity Wealth & 0.90 & 3.96 & 5.59 & 6.21 & 3.13 & 5.57 & 6.17 & 5.66 \\
\hline Liquid Wealth & 2.98 & 1.27 & 0.59 & 0.21 & 0.61 & 0.51 & 0.34 & 0.01 \\
\hline Consumption (real) & 1.06 & 0.98 & 1.13 & 1.73 & 1.07 & 1.01 & 1.24 & 1.70 \\
\hline
\end{tabular}

Notes: Male retiree age 65. Stochastic mortality. Panel A: Log-return stocks (bond yield): mean: 8.89\% (5.91\%), volatility: 25.3\% (2.1\%). Annual inflation: 2.2\%. PLA pricing assumptions: Mortality: DAV 2004 R (year 2013) plus trend, $G I R=3.5 \%, \omega_{r}=0.92, \omega_{q}=0.92$. Panel B: Log-return stocks (bond yield): mean: $0.7 \%$ (3.86\%), volatility: 30.0\% (1.04\%). Annual inflation: 1.6\%. PLA pricing assumptions: Mortality: DAV $2004 \mathrm{R}$ (year 2013) plus trend, $G I R=2.3 \%, \omega_{r}=0.92, \omega_{q}=0.92$. Panel C: as in B with $G I R=0 \%, \omega_{r}=0.90, \omega_{q}=0.5$. Source: Authors' calculation. 
Table 2: Expected Asset Allocations - Alternative Calibrations

\begin{tabular}{|c|c|c|c|c|c|c|c|c|}
\hline & \multicolumn{4}{|c|}{ Surplus Annuitization } & \multicolumn{4}{|c|}{ Surplus Lump Sum } \\
\hline & \multicolumn{4}{|c|}{ Age } & \multicolumn{4}{|c|}{ Age } \\
\hline & 65 & 75 & 85 & 95 & 65 & 75 & 85 & 95 \\
\hline \multicolumn{9}{|c|}{ A: Baseline Capital Market Calibration (1980 - 2012) } \\
\hline Stocks & 50.0 & 24.9 & 10.8 & 2.5 & 47.7 & 15.8 & 6.7 & 0.3 \\
\hline Bonds & 2.2 & 2.2 & 0.1 & 0.0 & 6.0 & 0.0 & 0.0 & 0.0 \\
\hline Annuities & 47.8 & 72.8 & 89.1 & 97.5 & 46.4 & 84.2 & 93.3 & 99.7 \\
\hline \multicolumn{9}{|c|}{ B: Crisis Capital Market Calibration (2000 - 2012) } \\
\hline Stocks & 3.7 & 1.3 & 0.3 & 0.7 & 4.2 & 0.3 & 0.0 & 0.0 \\
\hline Bonds & 35.8 & 13.8 & 7.0 & 1.8 & 20.7 & 7.6 & 4.9 & 0.2 \\
\hline Annuities & 60.5 & 84.9 & 92.7 & 97.5 & 75.1 & 92.1 & 95.1 & 99.8 \\
\hline \multicolumn{9}{|c|}{$\begin{array}{l}\text { C: Crisis Capital Market Calibration (2000 - 2012), GIR = 0, Minimum Surplus } \\
\text { Distribution }\end{array}$} \\
\hline Stocks & 9.9 & 1.9 & 0.3 & 0.6 & 4.9 & 0.1 & 0.0 & 0.0 \\
\hline Bonds & 66.9 & 22.4 & 9.4 & 2.7 & 11.4 & 8.3 & 5.2 & 0.1 \\
\hline Annuities & 23.2 & 75.7 & 90.3 & 96.7 & 83.7 & 91.6 & 94.8 & 99.9 \\
\hline
\end{tabular}

Notes: Male retiree age 65. Stochastic mortality. Panel A: Log-return stocks (bond yield): mean: 8.89\% (5.91\%), volatility: 25.3\% (2.1\%). Annual inflation: 2.2\%. PLA pricing assumptions: Mortality: DAV 2004 R (year 2013) plus trend, $G I R=3.5 \%, \omega_{r}=0.92, \omega_{q}=0.92$. Panel B: Log-return stocks (bond yield): mean: 0.7\% (3.86\%), volatility: 30.0\% (1.04\%). Annual inflation: 1.6\%. PLA pricing assumptions: Mortality: DAV 2004 R (year 2013) plus trend, $G I R=2.3 \%, \omega_{r}=0.92, \omega_{q}=0.92$. Panel C: as in B with $G I R=0 \%, \omega_{r}=0.90, \omega_{q}=0.5$. Source: Authors' calculation.

Table 3: Welfare Analysis

\begin{tabular}{|c|c|c|}
\hline & Surplus Annuitization & Surplus Lump Sum \\
\hline \multicolumn{3}{|c|}{ A: Baseline Capital Market Calibration (1980 - 2012) } \\
\hline Base Case & 20.5 & 27.4 \\
\hline Trending Mortality & 23.5 & 28.0 \\
\hline \multicolumn{3}{|c|}{ B: Crisis Capital Market Calibration (2000 - 2012) } \\
\hline PLA: $G I R=2.3 \% ; \omega_{q}=0.92 ; \omega_{r}=0.92$ & 24.0 & 32.7 \\
\hline PLA: $G I R=0 \% ; \omega_{q}=0.5 ; \omega_{r}=0.9$ & 17.7 & 27.6 \\
\hline
\end{tabular}

Notes: Male retiree age 65. Stochastic mortality. Panel A: Log-return stocks (bond yield): mean: 8.89\% (5.91\%), volatility: 25.3\% (2.1\%). Annual inflation: 2.2\%. PLA pricing assumptions: Mortality: DAV 2004 R (year 2013) plus trend, $G I R=3.5 \%, \omega_{r}=0.92, \omega_{q}=0.92$. Panel B: Log-return stocks (bond yield): mean: 0.7\% (3.86\%), volatility: 30.0\% (1.04\%). Annual inflation: 1.6\%. Source: Authors’ calculation. 